\title{
Research on Environmental Test On-line Detection Device Based on Flow Metrological Instrument
}

\author{
Meng Fanliang, Gao Senlin, Sun Quan, Zhang Xiaoping, Wang Xigang \\ Tianjin Institute of Metrological Supervision Testing, Tianjin 300192, China
}

Keywords: flow metrology meter; impact of ambient change; online dynamic measurement

\begin{abstract}
The metrological performance of flow meter should be tested under the condition of ambient temperature and humidity changes according to appendix A type evaluation outline of JJG 1033-2007 "Electromagnetic Flowmeter" verification procedures. In order to meet the requirements of the type of evaluation outline, an "environmental test on-line detection device based on flow metrological instrument" is developed. The pipe and the meter can be directly connected to this device. The metrological performance of the meter can be assessed and the environment's temperature and humidity can be controlled at the same time. Experts have identified that the device can fully meet the requirement that metrological performance of flow meter can be tested under the condition of ambient temperature and humidity changes.
\end{abstract}

\section{Introduction}

Flow meters are widely used and playing a great role in the construction of many aspects. It is very important to evaluate the type of flow meters, which is an important measure to guarantee the quality $^{[1]}$. However, at present, the measurement of the performance of the energy metering instrument is basically static measurement, that is, the instrument will be taken out of the test box after the environmental test to be done the meter performance test. It can not really realize the on-line measurement of meter measurement performance. In order to meet the demand of this kind of test, a set of environmental test on-line detection device based on flow metrological instrument was designed and manufactured. Using this device, the flow line can be directly access to the environmental test device, and the measured instrument can directly access the internal environment from the test device in the pipeline. During the whole test process, the overall instrument is in changing environmental conditions. The test data of the instrument can be observed through the observation window. On-line detection of the instrument can be realized. ${ }^{[2-4]}$

\section{Design index and basic structure}

\subsection{Technical parameters}

The required temperature and humidity parameters of the device are in Table 1 according to the technical specifications. 
Table 1 Temperature and Humidity Parameters

\begin{tabular}{|c|c|}
\hline Parameters & Value \\
\hline Temperature and humidity range & $(-20 \sim+60){ }^{\circ} \mathrm{C},(30 \sim 95) \% \mathrm{RH}$ \\
\hline Maximum Permissible Error of Temperature & High temperature: $\pm 2.0^{\circ} \mathrm{C} ;$ Low temperature: $\pm 3.0^{\circ} \mathrm{C}$ \\
\hline Maximum Permissible Error of Humidity & $(+2 \sim-3) \% \mathrm{RH}$ \\
\hline
\end{tabular}

\subsection{Outline Structure Design}

At present, LBS type water flow standard device, which are widely used, can complete detection work of $\Phi 65, \Phi 80, \Phi 100, \Phi 125, \Phi 150, \Phi 200$ caliber flow meter. The structure design fully takes into account the existing space of the laboratory. At the same time, it is very convenient to switch pipelines of different caliber instruments, so that a test device can complete the test of different caliber meters.

In order to ensure that the pipeline is fully connected to the environmental test device, the box is designed to be two parts, so that the pipeline can be completely put into the test device (Fig.1). It is a brand new design idea and concept. Material inside and outside the box is SUS304 stainless steel, and thickness is not less than $1.2 \mathrm{~mm}$. The insulating layer material is hard flame retardant polyurethane foam with a thickness of not less than $100 \mathrm{~mm}$, so as to achieve good heat preservation effect.

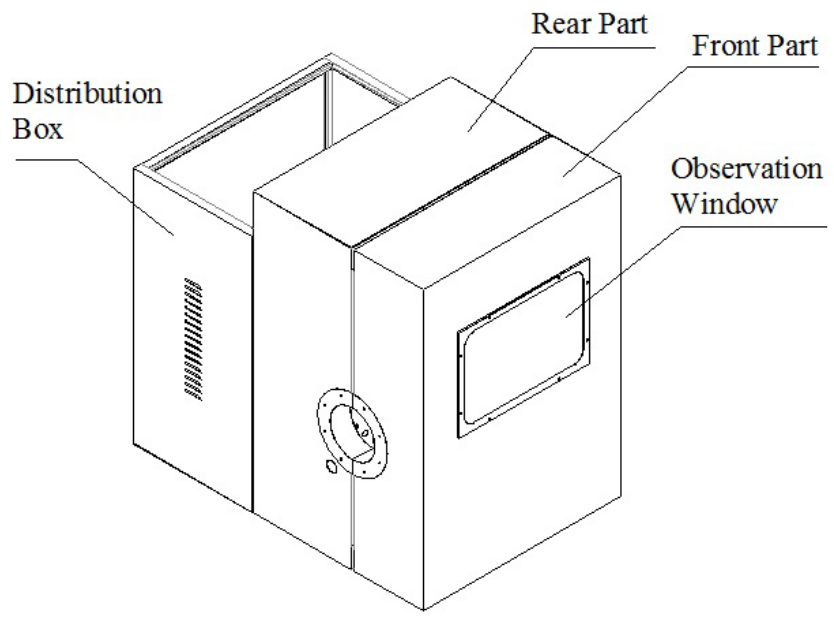

Fig.1 Outline Structure

\subsection{Connection design of different diameter pipeline}

The connecting part of the box body and the pipeline is designed to be a flange structure, and the flange is divided into two bodies. The flange can be fixed on the test device, and the through hole is formed when the two parts of the test device are combined together. The diameter of the through hole can be matched with the pipeline installed. Through the replacement of different diameter of the flange, we can switch the different diameter of the pipeline to achieve the different diameter of the instrument on line detection (Fig.2). 


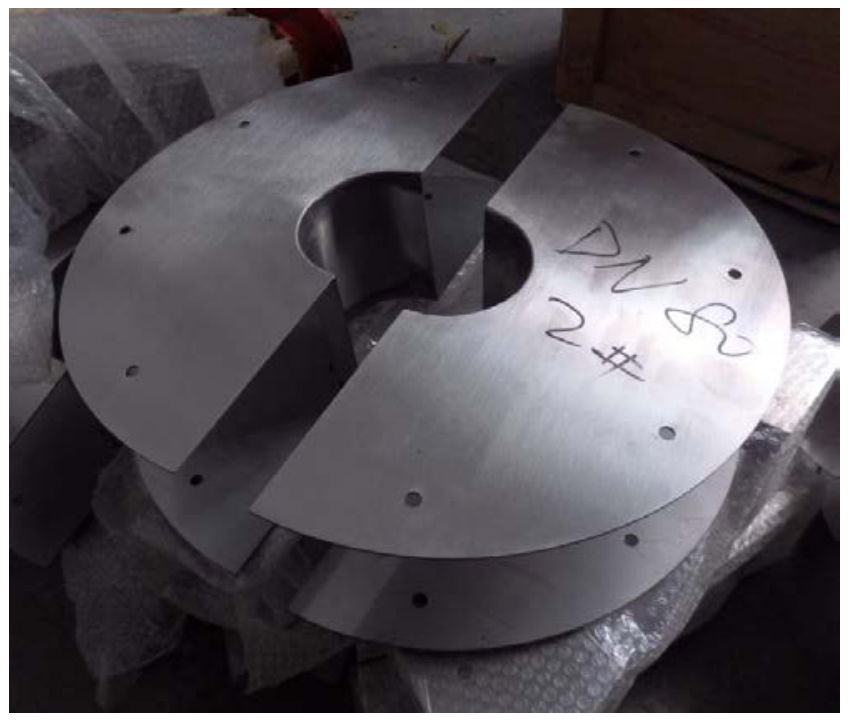

Fig. 2 Flange Structure

\subsection{Design of control system}

7 inch LCD color screen, which is touch controlled, is applied, and Chinese interface is used. The temperature and humidity can be controlled and there are other functions like over temperature protection, over pressure protection, water level control and temperature and humidity curve (Fig. 3).

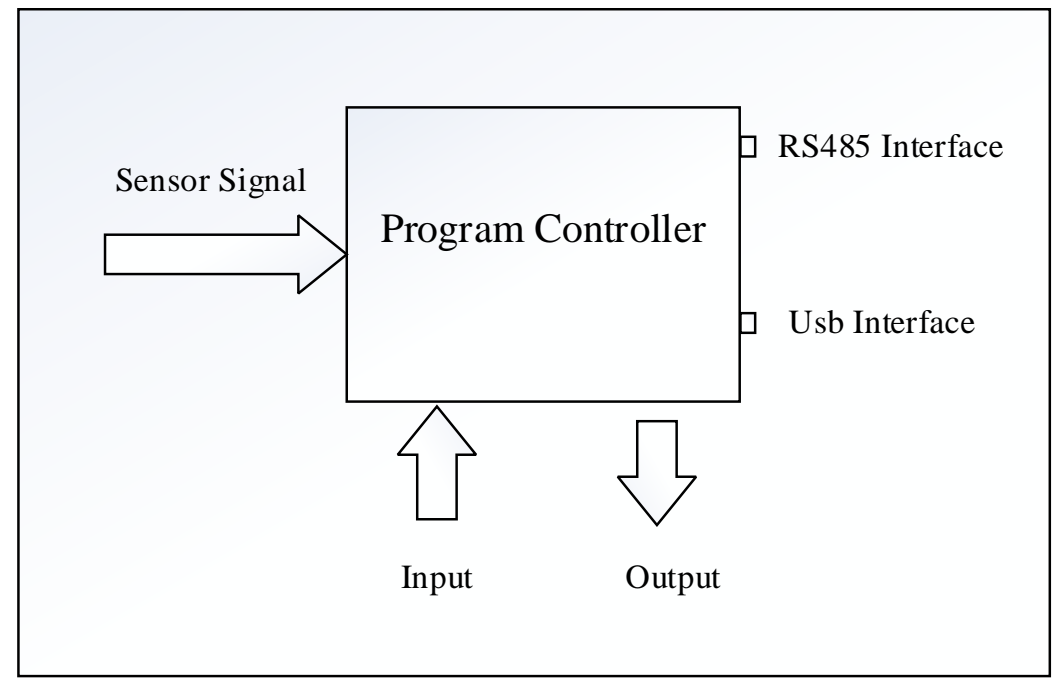

Fig. 3 Program Controller

In Fig. 3, RS485 interface is for centralized control. The input signal includes overload, over temperature, high water level and low water level, overpressure, under voltage, overheat, short circuit alarm signal. The output signal includes power supply, heating, refrigeration, ventilation, lighting and power switch signal.

\subsection{Design of hot and cold circulation system}

Refrigeration unit of high quality brand and environmental friendly refrigerant are selected. The instrument is equipped with a pressure sensor for detecting the working condition of the compressor, so as to monitor the refrigeration pressure. Low temperature connecting pipeline is made of high 
quality oxygen free copper tube. The heating part is made of high quality nickel chromium alloy electric heater, and is armored by 304 stainless steel. The hot and cold circulation system is PID regulated,which is implemented by SSR (Fig. 4).

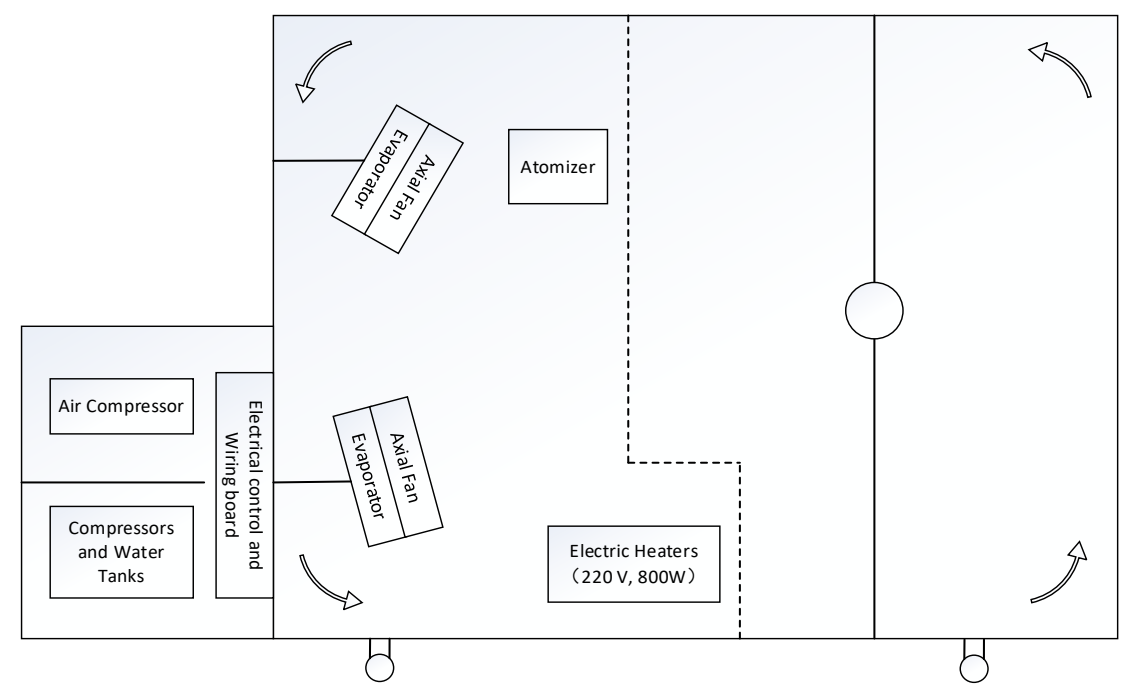

Fig. 4 Hot and Cold Circulation System

\subsection{Design of spray system}

The spray system adopts the electric heating steam humidification, and the electromagnetic valve is controlled by on-off adjustment system to control the humidification (Fig. 5). The main function of the regulator is to adjust the intensity of the injection. In addition, the water level controller is used to control the water level.

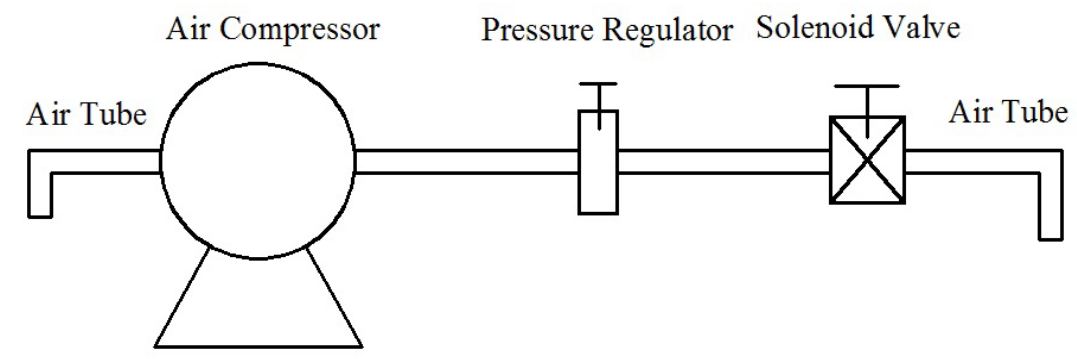

Fig. 5 Spray System

\section{Operation Effect}

\subsection{Test and Verification}

On the basis of JJF 1101-2003 calibration specification for the equipment of the environmental testing for temperature and humidity, the inspection device was calibrated by the multi-channel temperature and humidity display instrument Calibration results and data from the China Institute of Metrology showed the ability of the device can fully meet the technical requirements of design. ${ }^{[5]}$

The maximum error of its high temperature is $-0.6{ }^{\circ} \mathrm{C}$ and the maximum error of low temperature is $-0.8{ }^{\circ} \mathrm{C}$. The humidity maximum error of the instrument is $-0.9 \% \mathrm{RH}$.

\subsection{Operation Status}

At present, the device has been put into the actual on-line testing. The experimental results show 
that the development of the device can realize the on-line detection of the flow meter in the condition of temperature and humidity changing, and meet the technical requirements of the rules and specifications.

\section{Conclusion}

At present, the "environmental test on-line detection device based on flow metrological instrument" has been checked and accepted by the General Administration of Quality Supervision, Inspection and Quarantine of the People's Republic of China. The device can fully meet the requirements of online detection for different diameter flow meters like $\Phi$ 65、 $Ф 80 、 \Phi 100 、 \Phi$ 125、 $\Phi 150$ and $\Phi 200$, which is under different temperature and humidity conditions. The highlight of the device is to break through the traditional design concept. The test box body is divided into two halves and has a good sealing. The pipeline and the flow meter are directly connected to the environmental test device to realize the on-line detection in a real sense. At the same time, by changing the flange of the test case, the detection of different caliber flow meter is realized.

\section{Acknowledgements}

Project supported by AQSIQ of China(Grant No. 2015QK014) .

\section{References}

[1] AQSIQ. JJG 1033-2007, Electromagnetic Flowmeters [S]. China Metrology Publishing House,2007.

[2] Koushanfar F, Potkonjak M, Sangiovanni-Vincentelli A. On-line fault detection of sensor measurements[C]//Sensors, 2003. Proceedings of IEEE. IEEE, 2003, 2: 974-979.

[3] Partidário M R. Strategic environmental assessment: key issues emerging from recent practice[J]. Environmental impact assessment review, 1996, 16(1): 31-55.

[4] Guo Hui. The development of DN(15 200) mm water flow standard device [D]. Hebei University,2014.

[5] AQSIQ. JJF 1101-2003,Calibration Specification for the Equipment of the Environmental Testing for Temperature and Humidity[S]. China Metrology Publishing House,2003. 